\title{
Effect of High Fidelity Simulation Based Training Program on Interns Students' Knowledge and Skills about Management of Eclamptic Fits
}

\author{
Naglaa Zaki Hassan Roma, Lecturer \\ Obstetrics and Gynecological Nursing, Faculty of Nursing, Alexandria University \\ Sahar Anwar Rizk, Professor \\ Obstetrics and Gynecological Nursing, Faculty of Nursing, Alexandria University \\ Nefertiti Hassan Zaki, Professor \\ Obstetrics and Gynecological Nursing, Faculty of Nursing, Alexandria University
}

\begin{abstract}
Eclampsia represents one of the most common problems of pregnancy that lead to increased maternal and perinatal morbidity and mortality. Objective: Determine the effect of high fidelity simulation based training program on intern students' knowledge and skills about management of eclamptic fits. Setting: The (OSCE) lab at the Faculty of Nursing, Alexandria University and ElShatby Maternity University Hospital. Subjects: A simple random sample of 60 intern students were randomly divided into two equal group, a study and control group 30 for each group. Tools: Two tools were used: (I) Intern Students' Knowledge about Management of Eclamptic Fits Questionnaires (II) Intern Students' Skills about Management of Eclamptic Fits Observational Checklist. Results: The total mean scores of knowledge in the study group was (209.97+13.06) compared to (137.10+34.28) of the control group, and the total mean scores of skills in the study group was $(193.87+4.78)$ compared to (97.73 \pm 18.3$)$ of the control group after intervention. Conclusion: The study hypothesis is accepted, where the study group had higher knowledge and skills levels than the control group. Recommendations: Pre-service and in-service competency-based training on the high fidelity simulation based training should target all maternity nurses.
\end{abstract}

Keywords: High fidelity simulation; Intern students; Knowledge, Skills; Management of eclamptic fits.

\section{Introduction}

Hypertensive pregnancy disorders (HPD) represent one of the most common problems of pregnancy and lead to increased maternal perinatal morbidity and mortality $^{(1)}$. The prevalence of HPD is 8$10 \%$ of all pregnancies in the global population. It contributes to $10 \%$ to $15 \%$ of direct maternal deaths worldwide. In South Africa, HPD were the commonest direct causes of maternal deaths which, contributed to $19 \%-32 \%$ of all maternal deaths. While, in Egypt 2014, the prevalence of preeclampsia is $6 \%-8 \%$ of all pregnancies ${ }^{(2)}$.

Preeclampsia is a HPD occurring usually after the 20th weeks of gestation, characterized by hypertension (Blp $\geq 140 / 90$ $\mathrm{mmHg}$ ) with or without proteinuria $(\geq 300$ $\mathrm{mg} / 24$ hours) and edema. If not controlled, pre-eclampsia will lead to eclampsia which is characterized by fits, followed by coma, and has a high mortality rate ${ }^{(3)}$.

The majority of deaths due to preeclampsia and eclampsia can be avoidable through the provision of timely and effective care $^{(4)}$. Consequently, The WHO had developed recommendations to promote the best possible clinical practices for the management of preeclampsia and eclampsia $^{(5)}$.

Clinical teaching is a hallmark of nursing education. It is pivotally important in the development of competency in clinical practice. It also plays an important role in undergraduate nursing education. It provides an opportunity for nursing students to apply theory in practice, develop their problem solving, critical thinking, decision 
making and communication skills as well as improve their legal and ethical issues ${ }^{(6)}$.

Clinical teaching faces many challenges that can hinder the achievements of its goals. These challenges include: shortage of clinical faculty, lack access to clinical sites, decreased numbers of clinical areas available at specific dates and times and increase students' enrollment. Thus, these challenges affect students' preparation to be a competent and skillful nurse ${ }^{(7)}$. Therefore, clinical nurse instructors have curial role to prepare expert and competent graduate nurses for today's health settings, through incorporate innovative teaching strategies in clinical nursing education such as simulators which provides the skills that will be required in the $21^{\text {st }}$ century's healthcare environment to better preparation of nursing students ${ }^{(8)}$.

Simulation based learning is one innovative teaching strategies that have increasingly incorporated in clinical nursing education programs. It is the single most important trend in nursing education today and the way to move from learning to doing $^{(9)}$.

Clinical nursing teaching has historically used a variety of simulation methods such as models, case studies, role playing, games and multimedia presentations. High Fidelity human patient Simulators (HFS) are one of the main technology based tools being integrated into undergraduate nursing education such as the Noelle Gaumard ${ }^{(10,11)}$.

Using High Fidelity Simulation in clinical education has many benefits: it provides an opportunity for nursing students for practice nursing skills before engaging in clinical practice, thereby assuring that they have the knowledge to be confidence in providing safe and effective care ${ }^{(12)}$.

Nursing programs aim to create graduate nursing students proficient in making critical decisions regarding the care of patients with critical cases such as eclamptic women. In addition, health care administrators expect novice graduate students to perform with a higher degree of clinical competence that impacts the quality of patient care, improves patient' outcomes and enhances self-confidence ${ }^{(13,14)}$.

\section{Aim of the Study}

This study aimed to determine effect of high fidelity simulation based training program on intern students' knowledge and skills about management of eclamptic fits.

\section{Research Hypotheses}

1. Intern students who attend simulation based training program exhibit higher knowledge score than those who don't attend it.

2. Intern students who attend simulation based training program exhibit higher skills score than those who don't attend it.

\section{Materials and Method}

\section{Materials}

Design: A quasi-experimental research design was utilized in this study.

Setting: The study was conducted at Objective Structure Clinical Examination (OSCE) lab at the Faculty of Nursing, Alexandria University for training by using high fidelity simulator (the NoelleGaumard) about management of eclamptic fits and El-Shatby Maternity University Hospital affiliated to University of Alexandria for assessing the routine clinical training in the hospital about management of eclamptic fits.

Subjects: Intern students who are trained in eclamptic unit and intensive care units (approximately 60 intern students) were included in the study. Sample size was estimated according to Epi-Info program using the following parameters:

- Population size $=110$ intern students.

- Expected frequency $=50 \%$.

- Acceptable error $=10 \%$

- Confidence coefficient $=95 \%$ 
- Minimum sample size=51 intern students.

Intern students were randomly assigned to either control or study group about 30 for each group.

Tools: Two tools were developed by the researcher based on review of current relevant up dated literature:

Tool I: Intern Students' Knowledge about \begin{tabular}{llll}
\hline Management of & Eclamptic & Fits
\end{tabular} Questionnaires

It comprised two parts as follow:

Part I: Intern students' profile: It was developed by the researcher to collect data about: age, educational level, previous academic achievement and experience in nursing.

Part II: Intern Students' Knowledge about Management of Eclamptic Fits Questionnaires: This part was developed by the researcher after extensive review of recent and relevant literature to assess intern students' knowledge about eclamptic patients' management. It comprised 76 items in 6 main groups of questions as follow: general knowledge about preeclampsia and eclampsia $(\mathrm{N}=10)$, knowledge about $\mathrm{MgSO} 4(\mathrm{~N}=6)$, nurse role regarding administration of $\mathrm{MgSO} 4(\mathrm{~N}=10)$, nurse role before the seizure $(\mathrm{N}=25)$, nurse role during the seizure $(\mathrm{N}=11)$ and nurse role after the seizure $(\mathrm{N}=14)$. Intern student' response was varying to each item between incorrect answer (1), correct but not complete (2), correct and complete (3). The total score ranged between $76-228$. Intern student' knowledge was ranked as follow:

- Poor for total score $\leq 126$

- Fair for total score 127 - 202

- Good for total score $\geq 203-228$

Tool II: Intern Students' Skills about Management of Eclamptic Fits Observational Checklist

This tool was adapted from The WHO (2011) $\quad$ "Guidelines for Managing Complications in Pregnancy and Childbirth: A guide for midwives and doctors". It was used to assess Intern students' skills about eclamptic patients' management. It included 67 items in 4 main groups: nurse role before the seizure $(\mathrm{N}=28)$, nurse role during the seizure $(\mathrm{N}=12)$ nurse role of administer magnesium sulfate $(\mathrm{N}=17)$ and nurse role after the seizure $(\mathrm{N}=10)$. Intern student' skill was scored as follow: correctly done (3), incorrectly done (2) and not done (1).The total score ranged between 67 - 201

Intern student' skills were ranked as follow:

- Poor for a total score $\leq 111$

- Fair for a total score $112-178$

- Good for a total score $\geq 179-201$

\section{Method}

The study was executed according to the following steps:

- A written permission to conduct the study was obtained from the dean of the Faculty of Nursing, Alexandria University after explanation of the purpose of the study.

- Tools one was developed by the researcher based on extensive review of recent and relevant literature, tool two was adapted and modified from The WHO guidelines for Managing Complications in Pregnancy and Childbirth.

- Tool I and II were tested for content validity by a jury of five experts in the related field then the necessary modifications was done. The validity was $97 \%$ for tool I and $100 \%$ for tool II.

- The reliability of Tool I and II were ascertained by measuring the internal consistency of their items using the Cronbach alpha coefficient test. The two tool reliable as $\alpha=(0.994)$ for tool I and $\alpha=(0.995)$ for tool II.

- A pilot study was carried out on 6 intern students exclude from the selected subjects. 
- The researcher was attended training on the using of high fidelity simulator by expert in the related field.

- The study was conducted through three phases:

\section{Pre assessment phase:}

Intern students of both groups were assessed for their socio-demographic and knowledge about eclamptic patients' management by using tool I.

\section{Program development phase:}

High fidelity simulation based training program was entailed two main parts: 1. Theoretical part was included general knowledge about preeclampsia and eclampsia, knowledge about $\mathrm{MgSO}$, nurse role regarding administration of $\mathrm{MgSO} 4$, nurse role before the seizure, nurse role during the seizure and nurse role after the seizure.

2. Clinical part was included High fidelity simulators, Software eclamptic scenarios that was prepared by the researcher based on extensive review of recent and relevant literature and tested for content validity by a jury of 5 experts in the related field then the necessary modifications was done which included eclamptic cases as well as actions taken for these conditions.

III. Implementation phase: all intern students were assigned randomly into ten subgroups; each group was contained six intern students for the purpose of the demonstration.

- For the study group: The program was implemented in 2 weeks by the researcher. Six sessions was scheduled 3 session / week in the morning (4hours each). The training course was reflected an 8hour didactic with a 16 hour clinical experience at simulate clinical environment SCE, over a period of approximately 20 weeks from $15 / 9$ to $20 / 1 / 2018$. All didactic content in the course was frontloaded followed by simulation. The program was conducted on six sessions as follow:

- Session (1) was included a didactic part about management of eclamptic fits was followed by demonstration nursing student role in administer magnesium sulphate and managing of eclamptic fits.

- Session (2) was included a didactic part about obstetric emergency in eclamptic patients.

- Sessions (3-6) were an included emergency intervention that was applied in case of eclamptic fits. Then the study subjects were exposed to a variety of scenarios about eclamptic patients' management as well as fits management.

- Each scenario was ran for approximately 15 to 20 minutes, during which time the intern student was able to ask questions, perform interventions for eclamptic patients as well as redemonstrated it by using high fidelity simulator. Illustrate handout about caring for eclamptic patients' knowledge was distributed after implementation of the program as a reference.

\section{Evaluation of the effectiveness of training program:}

Intern student' knowledge and skills about management of eclamptic fits was reassessed twice immediately and after two months following the training program using the study tools.

\section{Ethical considerations:}

For each recruited subject the following issues were considered: securing the subject's informed written consent, keeping her privacy and right to withdrew at any time as well as assuring confidentiality of her data. 


\section{Statistical Analysis}

Data analysis was carried out on window XP using statistical Package for Social Sciences (SPSS) version 21 program. The collected data was categorized, coded, computerized, tabulated and analyzed.

\section{Results}

Table (1) indicates absence of any statistically significant differences between the study and control groups in relation to their age, level of education, previous academic achievement, years of experience in nursing and residence. Specifically, the vast majority of the study and control group $(83.33 \%$ \& $90 \%)$ respectively were less than 23 years old, had bachelor degrees and their experience were less than one year, while the rest of both group aged between 23 to 25 years old had a condensed bachelor degrees, and their experience were one year or more. In relation to original residence, the table also presents that $66.67 \% \& 53.33 \%$ respectively of study and control group were urban dwellers, while $33.33 \%$ \& $46.67 \%$ of them were rural dwellers.

Table (2) clarify that there was a highly statistical significant difference between total mean knowledge score of the study groups before, immediately after and two months after a didactic part of intervention, $(\mathrm{F}=252.597, \mathrm{P}=.000)$. It was also found that, knowledge mean scores of the study group was lower before intervention while, it increased significantly after didactic part of intervention regarding eclamptic patients' management in relation to general knowledge about preeclampsia and eclampsia, knowledge about Mgso4, nurse's role regarding administration of $\mathrm{MgSO} 4$, nurse's role before the seizure, nurse's role during the seizure and nurse's role after the seizure $(\mathrm{F}=71.834, \quad \mathrm{P}=0.000), \quad(\mathrm{F}=99.364$, $\mathrm{P}=0.000), \quad(\mathrm{F}=87.690, \quad \mathrm{P}=0.000)$, $(\mathrm{F}=137.643, \quad \mathrm{P}=0.000), \quad(\mathrm{F}=216.283$, $\mathrm{P}=0.000),(\mathrm{F}=98.366, \mathrm{P}=0.000)$ respectively.

Table (3) clarify that there was no statistical significant difference between total mean knowledge score of the study groups before, immediately after and two months after a didactic part of intervention $(\mathrm{F}=1.78, \mathrm{P}=0.178)$. It was also found that there was no statistical significant difference between mean knowledge scores of the control before, immediately and two months after a didactic part of intervention in relation to: nurse's role regarding administration of $\mathrm{MgSO} 4$, nurse's role before the seizure and nurse's role during the seizure, nurse's role after the seizure $(\mathrm{F}=1.895, \mathrm{P}=0.160), \quad(\mathrm{F}=0.970, \mathrm{P}=0.385)$, $(\mathrm{F}=0.442, \quad \mathrm{P}=0.645), \quad(\mathrm{F}=1.560, \quad \mathrm{P}=0.219)$ respectively. However, there was a statistical significant difference between mean knowledge scores of the control before, immediately and two months after a didactic session in relation to: General knowledge about preeclampsia and eclampsia, knowledge about Mgso4 ( $\mathrm{F}=10.396$, $\mathrm{P}=0.000),(\mathrm{F}=8.349, \mathrm{P}=0.001)$ respectively.

Table (4) illustrates the number and percent distribution of the study and control groups regarding their knowledge about management of eclamptic fits before, immediately after and two months after intervention $(\mathrm{n}=30)$. It clarify that, before intervention $(56.67 \%, 43.33 \%),(46.67 \%$, $53.33 \%$ ) respectively of the study and control group obtained fair and poor total knowledge score. The difference between groups was no statistically significant $(\mathrm{p}=0.438)$. On the other hand, immediately after intervention $90 \%$ of study compared to only $(3.33 \%)$ of the control group obtained good total knowledge score. The difference between groups was statistically significant $(\mathrm{p}=0.000)$. After two months of intervention about two third $(66.67 \%)$, of the study group compared to only $(3.33 \%)$ of the control group obtained good total knowledge score. The difference between groups was highly statistically significant $(\mathrm{p}=0.000)$.

Table (5) represents that, there was highly statistical significant difference between total mean skills score of the study groups before, immediately after and two months after intervention, ( $\mathrm{F}=972.089$, 
$\mathrm{P}=0.000$ ). It was also found that, the mean scores of the study group increased significantly after training using high fidelity simulator in performing all skills related eclamptic patients' management as follow: nurse's role before the seizure, nurse's role during the seizure, nurse's role after the seizure and nurse's role of administer magnesium sulfate $(\mathrm{F}=546.075, \mathrm{P}=0.000)$, $(\mathrm{F}=607.566, \quad \mathrm{P}=0.000), \quad(\mathrm{F}=287.542$, $\mathrm{P}=0.000), \quad(\mathrm{F}=578.245, \quad \mathrm{P}=0.000)$ respectively.

Table (6) reveals that, there was no statistical significant difference between study and among the control group total skills score before, immediately after and two months after intervention $(\mathrm{F}=0.834$, $\mathrm{P}=0.440$ ). It was also observed that the mean skills score of the control group indicates no statistically significantly difference after routine clinical training in the hospital by clinical preceptors in performing almost skills related to eclamptic patients' management as follow: nurse's role before the seizure, nurse's role during the seizure nurse's role after the seizure and nurse's role of administer magnesium sulfate $(\mathrm{F}=0.195, \mathrm{P}=0.823), \quad(\mathrm{F}=2.275, \mathrm{P}=0.112)$ $(\mathrm{F}=1.263, \mathrm{P}=0.290), \quad(\mathrm{F}=1.960, \mathrm{P}=0.150)$ respectively.

Table (7) shows the number and percent distribution of the study and control groups regarding their skills about management of eclamptic fits before, immediately after and two months after intervention $(n=30)$. It clarify that, before intervention, the majority $(83.33 \%)$ of the study group compared to two thirds $(66.67 \%)$ of control group had poor skills about management of eclamptic fits. The difference between groups denotes no statistically significant differences between both groups $(p=0.139)$. On the other hand, immediately after intervention it was noticed that the majority $(86.67 \%)$ of the study group compared to none of the control group had good skills about management of eclamptic fits. In contrast, $73.33 \%$ in the control group compared to none of study group had poor skills about management of eclamptic fits. The difference between groups was statistically significant $(\mathrm{p}=0.000)$. After two months of intervention about, it was noticed the majority $(83.33 \%)$ of the study group had good skills about management of eclamptic fits, compared to $(80 \%)$ of the control group had poor skills about management of eclamptic fits. The difference between groups was statistically significant $(\mathrm{p}=0.000)$. Furthermore, it was noticed that the total score of skills among study group increased significantly after training about eclamptic patients' management using high fidelity simulator $(\mathrm{p}=0.000)$, on the other hand the control group signify the same level of skills before and after routine clinical training in the hospital therefore, no statistically significant difference was noticed between total scores of skills $(\mathrm{p}=0.954)$.

Table (8): exhibits the relationship between total knowledge score and total skills score about management of eclamptic fits among study group before, immediately after and two months after intervention $(n=30)$. Regarding before intervention, it was found that, there was a negative statistically correlation between total knowledge score and total skills score. Where, $56.67 \%$, $43.33 \%$ respectively of the study group who obtained fair and poor total knowledge score, had $16.67 \%, 83.33 \%$ fair and poor total skills score respectively. There was statistical significant difference $(\mathrm{p}=0.052)$. While, immediately after intervention, it was observed that, there was a positive statistically correlation between total knowledge score and total skills score. Where, $90 \%, 10 \%$ respectively of the study group, who obtained good and fair total knowledge score, had $86.67 \%, 13.33 \%$ respectively of good and fair total skills score respectively. There was no statistical significant difference $(\mathrm{p}=0.097)$. Two months after intervention, it was observed that, there was a positive statistically correlation between total knowledge score and total skills score. Where, 66.67\%, $33.33 \%$ respectively of the study group who 
obtained good and fair total knowledge score, had $83.33 \%, 16.67 \%$ respectively of good and fair total skills score respectively. The difference was statistical significant $(\mathrm{p}=0.030)$.

Table (9) shows the relationship between total knowledge score and total skills score about management of eclamptic fits among control group before, immediately after and two months after intervention $(n=30)$. Considering before intervention, it was found that, there was a positive statistically correlation between total knowledge score and total skills score. Where, 46.67\%, $53.33 \%$ respectively of the control group who obtained fair and poor total knowledge score, had $33.33 \%, 66.67 \%$ fair and poor total skills score respectively. There was statistical significant difference $(p=0.019)$. While, immediately after intervention, there was a negative statistically correlation between total knowledge score and total skills score. It was observed that $73.33 \%$ \& $23.33 \%$ respectively, of the control group who obtained fair or poor knowledge, $26.67 \%$ \& $73.33 \%$ respectively of them had fair skills. There was statistical significant difference $(\mathrm{p}=0.000)$. As well as, two months after intervention score, there was a negative statistically correlation between total knowledge scores and total skills score. Where $83.33 \%$ \& $13.33 \%$ respectively, of the control group who obtained fair or poor knowledge, $20.0 \%$ \& $80.0 \%$ respectively of them had fair skills. The difference was statistically significant $(\mathrm{p}=0.000)$.

\section{Discussion}

The results of the current study revealed that total mean score of the knowledge in both groups before the intervention (table 2) were approximately similar $(126.23 \pm 19.19)$ and (125.60 \pm 27.15$)$ for study and control group respectively. No statistically significant difference was found $(\mathrm{P}=0.917)$. Total mean scores of knowledge immediately after the intended intervention (table 3) for the two groups increased to $(209.97 \pm 13.06)$ and $(137.10 \pm 34.28)$ of study and control group respectively in the favor of the study group with highly statistical significant difference between the two groups $(\mathrm{P}=0.000)$. Finally two months after the intervention (table 4) total mean scores for the two groups were $(201.57 \pm 15.68)$ and $(135.40 \pm 30.57)$ of study and control group respectively in the favor of the study group with highly statistical significant difference between the two groups, in favor of the study group $(\mathrm{P}=0.000)$.

This is in line with the study of Abusaad and Ebrahem (2015) in Mansura, Egypt, "The changes on knowledge, confidence and skills accuracy of nursing students at a simulated based setting versus traditional education" where they found that there was a statistical significant difference in the total mean scores of knowledge immediate and after three months of the intervention. It was demonstrated that the total mean score of the knowledge in both groups pre the intervention were approximately similar $(10.12 \pm 2.42)$ for traditional group and $(10.40 \pm 2.77)$ for the simulated group. No statistically significant difference was found $(\mathrm{P}=0.592)$. Immediately after the intervention the total mean scores for the two groups improved to $17.70 \pm 2.82$ and $20.08 \pm 1.71$ for traditional group and simulated group respectively with statistical significant difference between the two groups. The total mean score of knowledge after 3 months improved than pretest in the traditional group was 7.26 \pm 3.61 compared to $9.94 \pm 3.51$ in the simulated group, with statistical significant difference $(\mathrm{P}=0.002)^{(15)}$.

The results of the current study revealed that highly significant difference was detected between the study and control groups in relation to total skills score immediately after and two months after intervention (table 7). In relation to before intervention scores, the difference between groups was no statistically significant $(\mathrm{P}=0.139)$. Regarding immediately after and two months after intervention scores, the difference between groups were statistically significant $(\mathrm{P}=0.000)$ respectively. Furthermore, it was noticed that the total skills test scores of the study group increased significantly after training about management of eclamptic fits using high fidelity simulator $(\mathrm{P}=0.000)$, on the other hand, the control group signify the same level of skills before and after didactic session therefore, no 
statistically significant difference was noticed between total scores of skills ( $\mathrm{p}=0.954)$.

The current finding is consistent with the study of Nuraini et al. (2015), in Indonesia on "Human patient simulation to improve the attitude of the nursing students" they showed that a significant difference on the attitude (performance) of the intervention group after the intervention $(\mathrm{P}=0.000)$. Whereas, the control group showed no statistically significant difference on the attitude $(\mathrm{P}=$ 0.094). Also, they stated that the human patient simulation improved the attitude of the nursing students before having the actual learning experience with the patients at the hospital. Thus, they recommended using human patient simulation to prepare the nursing students prior to clinical internship ${ }^{(16)}$.

The results of present study revealed that there is a statistically positive correlation between study group' knowledge and their skills immediately after and two months after intervention about management of eclamptic fits $(\mathrm{P}=0.097),(\mathrm{P}=0.030)$ respectively (table 8 ). This may be due to the fact that the study group gained their knowledge from PowerPoint presentation and through the use of different learning activities during simulation based training sessions such as questioning, simulation exercises, scenarios, debriefing and eclamptic patients' management checklist skills handout. According to the literature review referred to eclamptic patients' management body of knowledge is necessary to help nurse students to identify, organize and interpret preeclamptic/eclamptic women' needs systematically and accurately in order to make comprehensive, valid nursing assessment and $\operatorname{diagnosis}^{(17)}$.

The results of present study revealed that there is a statistically negative correlation between control group' knowledge and their skills immediately after and two months after intervention about management of eclamptic fits $(\mathrm{P}=0.000),(\mathrm{P}=0.000)$ respectively (table $9)$. This may be due to the control gained their knowledge through the PowerPoint presentation and they did not have training about eclamptic patients' management using high fidelity simulator. Also, there are several problems of clinical hospital environment reported to researcher by intern students. These problems such as unfamiliar environment that affect negatively on their performance. The results of the current study suggested that high fidelity simulation based training program has positive improvement of intern students' knowledge and skills about management of eclamptic fits. However, more researches are needed to evaluate such effectiveness.

\section{Conclusion}

The study hypothesis is accepted. Where the study group had higher knowledge and skills levels than the control group. High fidelity simulation based training program is a valuable tool in preparing intern students for managing eclampsia cases as well as maintaining, retention of knowledge and mastering the nursing skills for managing these cases in reality.

\section{Recommendations}

- Ensure an adequate number of dedicated simulation faculty with training and expertise in the pedagogy of simulation.

- Pre-service and in-service competency-based training on the high fidelity simulation based training should target all maternity nurses.

- Support the development of simulation leaders among the faculty.

- Evaluate simulation experiences using valid and reliable instruments.

Further researches should be carried out to:

- Conduct a similar study at different maternity settings on a large scale.

- Explore the effect of high fidelity simulation based training program on other problems encountered during the maternity cycle e.g. postpartum hemorrhage. 
Table (1): Number and percent distribution of the study subjects according to their sociodemographic characteristics

\begin{tabular}{|c|c|c|c|c|c|}
\hline \multirow[t]{2}{*}{ Socio-demographic characteristics } & \multicolumn{2}{|c|}{$\begin{array}{l}\text { Study group } \\
\quad(\mathbf{N}=\mathbf{3 0})\end{array}$} & \multicolumn{2}{|c|}{$\begin{array}{l}\text { Control group } \\
\qquad(\mathbf{N}=\mathbf{3 0})\end{array}$} & \multirow[t]{2}{*}{$\begin{array}{c}\mathrm{F} / \chi^{2} \\
(\mathbf{P})\end{array}$} \\
\hline & No & $\%$ & No & $\%$ & \\
\hline \multicolumn{6}{|l|}{ Age in years: } \\
\hline$-<23$ & 25 & 83.33 & 27 & 90.00 & 0.577 \\
\hline$-23-25$ & 5 & 16.67 & 3 & 10.00 & $(0.706)$ \\
\hline \multicolumn{6}{|l|}{ Original residence: } \\
\hline - Urban & 20 & 66.67 & 16 & 53.33 & 1.111 \\
\hline - Rural & 10 & 33.33 & 14 & 46.67 & $(0.292)$ \\
\hline \multicolumn{6}{|l|}{ Level of education: } \\
\hline - Bachelor & 25 & 83.33 & 27 & 90.00 & 0.577 \\
\hline - Condensed bachelor & 5 & 16.67 & 3 & 10.00 & $(0.706)$ \\
\hline \multicolumn{6}{|l|}{ Previous academic achievement: } \\
\hline$-\mathrm{B}+$ & 2 & 06.70 & 0 & 00.00 & \\
\hline$-\mathrm{B}$ & 10 & 33.33 & 8 & 26.67 & 2.744 \\
\hline$-\mathrm{B}-$ & 10 & 33.33 & 11 & 36.67 & \\
\hline$-\mathrm{C}+$ & 8 & 26.67 & 11 & 36.67 & \\
\hline \multicolumn{6}{|l|}{ Years of experience in nursing: } \\
\hline$-<1$ & 25 & 83.33 & 27 & 90.00 & 0.577 \\
\hline$-1-4$ & 5 & 16.67 & 3 & 10.00 & $(0.706)$ \\
\hline
\end{tabular}

$\chi^{2}(P):$ Chi-Square Test \& $P$ for $\chi^{2}$ Test FET (P): Fisher Exact Test \& P for FET-Test *: Significant at $P \leq 0.05$

Table (2): The mean differences among study group regarding their knowledge about management of eclamptic fits before, immediately after and two months after intervention $(\mathbf{n}=30)$

\begin{tabular}{|c|c|c|c|c|c|}
\hline \multirow{3}{*}{ Knowledge } & \multicolumn{3}{|c|}{ Study Group $(\mathbf{N}=\mathbf{3 0})$} & \multirow{3}{*}{$\mathbf{F}$} & \multirow{3}{*}{$\begin{array}{l}\text { Sig. }(2- \\
\text { tailed }\end{array}$} \\
\hline & $\begin{array}{c}\text { before } \\
\text { intervention }\end{array}$ & $\begin{array}{c}\text { immediately } \\
\text { after } \\
\text { intervention }\end{array}$ & $\begin{array}{c}\text { two months } \\
\text { after } \\
\text { intervention } \\
\end{array}$ & & \\
\hline & Mean \pm SD & Mean \pm SD & Mean \pm SD & & \\
\hline $\begin{array}{l}\text { General knowledge } \\
\text { about preeclampsia and } \\
\text { eclampsia }\end{array}$ & $20.50 \pm 4.19$ & $29.13 \pm 1.25$ & $27.23 \pm 2.61$ & 71.834 & $.000 *$ \\
\hline $\begin{array}{l}\text { knowledge about } \\
\text { MgSO4 }\end{array}$ & $9.50 \pm 2.43$ & $17.07 \pm 1.74$ & $14.03 \pm 2.44$ & 99.364 & $.000^{*}$ \\
\hline $\begin{array}{l}\text { Nurse's role regarding } \\
\text { administration of } \\
\text { MgSO4. }\end{array}$ & $15.93 \pm 4.83$ & $26.60 \pm 2.93$ & $24.87 \pm 2.76$ & 87.690 & $.000^{*}$ \\
\hline $\begin{array}{l}\text { Nurse's role before the } \\
\text { seizure }\end{array}$ & $43.60 \pm 11.37$ & $68.87 \pm 4.61$ & $70.00 \pm 2.74$ & 137.643 & $.000 *$ \\
\hline $\begin{array}{l}\text { Nurse's role during the } \\
\text { seizure }\end{array}$ & $17.20 \pm 3.91$ & $31.07 \pm 3.04$ & $31.07 \pm 2.00$ & 216.283 & $.000^{*}$ \\
\hline $\begin{array}{l}\text { Nurse's role after the } \\
\text { seizure }\end{array}$ & $19.50 \pm 4.02$ & $37.23+5.13$ & $34.37 \pm 6.16$ & 98.366 & $.000 *$ \\
\hline Total knowledge score & $126.23+19.19$ & $209.97 \pm 13.06$ & $201.57 \pm 15.68$ & 252.597 & $.000 *$ \\
\hline
\end{tabular}


Table (3): The mean differences among control group regarding their knowledge about management of eclamptic fits before, immediately after and two months after intervention $(\mathbf{n}=\mathbf{3 0})$

\begin{tabular}{|c|c|c|c|c|c|}
\hline \multirow{3}{*}{ Knowledge } & \multicolumn{3}{|c|}{ Control Group $(\mathrm{N}=30)$} & \multirow{3}{*}{$\mathbf{F}$} & \multirow{3}{*}{$\begin{array}{l}\text { Sig. }(2- \\
\text { tailed }\end{array}$} \\
\hline & $\begin{array}{c}\text { Before } \\
\text { Intervention }\end{array}$ & $\begin{array}{c}\text { immediately } \\
\text { after } \\
\text { intervention }\end{array}$ & $\begin{array}{l}\text { two months } \\
\text { after } \\
\text { intervention } \\
\end{array}$ & & \\
\hline & Mean \pm SD & Mean \pm SD & Mean \pm SD & & \\
\hline $\begin{array}{l}\text { General knowledge } \\
\text { about preeclampsia and } \\
\text { eclampsia }\end{array}$ & $19.57 \pm 4.90$ & $24.10 \pm 3.79$ & $22.83 \pm 3.60$ & 10.396 & $.000^{*}$ \\
\hline $\begin{array}{l}\text { knowledge about } \\
\text { MgSO4 }\end{array}$ & $8.97+2.30$ & $11.60+4.00$ & $10.90 \pm 3.14$ & 8.349 & $.001 *$ \\
\hline $\begin{array}{l}\text { Nurse's role regarding } \\
\text { administration of } \\
\text { MgSO4. }\end{array}$ & $17.47 \pm 4.64$ & $15.93 \pm 4.24$ & $15.93 \pm 4.24$ & 1.895 & .160 \\
\hline $\begin{array}{l}\text { Nurse's role before the } \\
\text { seizure }\end{array}$ & $44.07 \pm 11.72$ & $48.13 \pm 15.79$ & $46.73 \pm 14.08$ & .970 & .385 \\
\hline $\begin{array}{l}\text { Nurse's role during the } \\
\text { seizure }\end{array}$ & $15.40 \pm 3.84$ & $15.87 \pm 6.14$ & $16.40 \pm 5.50$ & .442 & .645 \\
\hline $\begin{array}{l}\text { Nurse's role after the } \\
\text { seizure }\end{array}$ & $20.13 \pm 4.68$ & $21.47 \pm 7.92$ & $22.60 \pm 7.52$ & 1.560 & .219 \\
\hline Total knowledge score & $125.60 \pm 27.15$ & $137.10 \pm 34.28$ & $135.40 \pm 30.57$ & 1.781 & .178 \\
\hline
\end{tabular}

$F=$ F Test

*: Significant at $P \leq 0.05$

Table (4): Number and percent distribution of the study and control groups regarding their knowledge about management of eclamptic fits before, immediately after and two months after intervention $(n=30)$

\begin{tabular}{|c|c|c|c|c|c|c|}
\hline \multirow[t]{2}{*}{ Variable } & \multirow{2}{*}{$\begin{array}{l}\text { Total } \\
\text { knowledge } \\
\text { Test }\end{array}$} & \multicolumn{2}{|c|}{$\begin{array}{c}\text { Study group } \\
(\mathbf{N}=\mathbf{3 0})\end{array}$} & \multicolumn{2}{|c|}{$\begin{array}{c}\text { Control group } \\
(\mathbf{N}=\mathbf{3 0})\end{array}$} & \multirow{2}{*}{$\begin{array}{c}\text { Pearson } \\
\text { chi - Square } \\
\text { test P }\end{array}$} \\
\hline & & No & $\%$ & No & $\%$ & \\
\hline $\begin{array}{l}\text { before } \\
\text { intervention }\end{array}$ & $\begin{array}{l}\text { Good } \\
\text { Fair } \\
\text { Poor } \\
\end{array}$ & $\begin{array}{c}0 \\
17 \\
13 \\
\end{array}$ & $\begin{array}{l}00.00 \\
56.67 \\
43.33 \\
\end{array}$ & $\begin{array}{c}0 \\
14 \\
16 \\
\end{array}$ & $\begin{array}{l}00.00 \\
46.67 \\
53.33 \\
\end{array}$ & $\begin{array}{c}0.601 \\
(0.438)\end{array}$ \\
\hline $\begin{array}{l}\text { immediately } \\
\text { after } \\
\text { intervention }\end{array}$ & $\begin{array}{l}\text { Good } \\
\text { Fair } \\
\text { Poor } \\
\end{array}$ & $\begin{array}{c}27 \\
3 \\
0 \\
\end{array}$ & $\begin{array}{l}90.00 \\
10.00 \\
00.00 \\
\end{array}$ & $\begin{array}{c}1 \\
22 \\
7 \\
\end{array}$ & $\begin{array}{l}03.33 \\
73.33 \\
23.33 \\
\end{array}$ & $\begin{array}{c}45.583 \\
(0.000)^{*}\end{array}$ \\
\hline $\begin{array}{l}2 \text { months after } \\
\text { intervention }\end{array}$ & $\begin{array}{l}\text { Good } \\
\text { Fair } \\
\text { Poor }\end{array}$ & $\begin{array}{c}20 \\
10 \\
0 \\
\end{array}$ & $\begin{array}{l}66.67 \\
33.33 \\
00.00 \\
\end{array}$ & $\begin{array}{c}1 \\
25 \\
4 \\
\end{array}$ & $\begin{array}{l}03.33 \\
83.33 \\
13.33 \\
\end{array}$ & \multirow{2}{*}{$\begin{array}{l}27.619 \\
(0.000)^{*}\end{array}$} \\
\hline Marginal homc & neity Test (P) & \multicolumn{2}{|c|}{$\begin{array}{c}56.230 \\
(0.000)^{*}\end{array}$} & \multicolumn{2}{|c|}{$\begin{array}{c}14.625 \\
(0.001)^{*}\end{array}$} & \\
\hline
\end{tabular}

*Significant at $p \leq 0.05$ 
High Fidelity Simulation, Eclamptic Fits Management

Table (5): Correlation between the study subjects according to their reproductive health and maternal confidence

\begin{tabular}{|c|c|c|c|c|c|c|c|}
\hline Data & \multicolumn{2}{|c|}{$\begin{array}{c}\text { Negative } \\
(\mathrm{N}=62)\end{array}$} & \multicolumn{2}{|c|}{$\begin{array}{c}\text { Moderate } \\
(\mathrm{N}=70)\end{array}$} & \multicolumn{2}{|c|}{$\begin{array}{c}\text { Positive } \\
(\mathrm{N}=28)\end{array}$} & $\begin{array}{l}\text { Significant } \\
\text { value ( p) }\end{array}$ \\
\hline \multicolumn{8}{|l|}{ Gravidity } \\
\hline - $\quad$ First time & 57 & 91.9 & 66 & 46.3 & 21 & 75 & \multirow[t]{2}{*}{0.855} \\
\hline - $\quad$ Abortion & 5 & 8.1 & 4 & 5.7 & 7 & 25 & \\
\hline \multicolumn{8}{|l|}{ Methods of delivery } \\
\hline - $\quad$ Vaginal delivery & 30 & 48.4 & 40 & 57.2 & 18 & 64.3 & \multirow[t]{2}{*}{$0.001 *$} \\
\hline - c- Section & 32 & 51.6 & 30 & 42.8 & 10 & 35.7 & \\
\hline \multicolumn{8}{|l|}{ Gender of baby } \\
\hline - $\quad$ Male & 30 & 48.4 & 62 & 88.6 & 28 & 100 & \multirow[t]{2}{*}{0.470} \\
\hline - Female & 32 & 51.6 & 8 & 11.4 & 0 & 0.0 & \\
\hline \multicolumn{8}{|l|}{ Pregnancy planed } \\
\hline - $\quad$ Planed & 54 & 87.1 & 60 & 85.8 & 26 & 42.8 & \multirow[t]{2}{*}{$0.001 *$} \\
\hline - $\quad$ Not planed & 8 & 12.9 & 10 & 14.2 & 2 & 7.2 & \\
\hline \multicolumn{8}{|c|}{ Attendance of antenatal visits } \\
\hline - Yes & 50 & 80.6 & 60 & 85.8 & 18 & 64.3 & \multirow[t]{2}{*}{$0.000^{*}$} \\
\hline$-\quad$ No & 12 & 19.4 & 10 & 14.2 & 10 & 35.7 & \\
\hline
\end{tabular}

*Significant at $p \leq 0.05$ 


\section{References}

1. Unicef and the Government of Canada: Accelerating the Movement to End Child, Early and Forced Marriage, 2017.

2. World Health Organization. WHO recommendations on postnatal care of the mother and newborn. Geneva: World Health Organization; 2013.

3. Mammie W, Prance, and Celia M. Early motherhood: a qualitative study exploring the experiences of African Australian teenage mothers in greater Melbourne, Australia. BMC Public Health. 2015; 15: 873.

4. WHO. Global health estimates 2015: deaths by cause, age, sex, by country and by region, 2000-2015. Geneva: WHO; 2016.

5. Gjerdingen DK, Froberg DG, Chaloner KM, McGovern PM. Changes in women's physical health during the first postpartum year. Arch Fam Med. 1993; 2(3):277-283.

6. Ruchala PL, James DC. Social support, knowledge of infant development, and maternal confidence among adolescent and adult mothers. J Obstet Gynecol Neonatal Nurs. 1997; 26(6):685-689. doi: 10.1111/j.15526909.1997. tb02743.x.

7. Lugina HI, Christensson $\mathrm{K}$, Massawe $\mathrm{S}$, Nystrom L, Lindmark G. Change in maternal concerns during the 6 weeks postpartum period: a study of primaparous mothers in Dar es Salaam, Tanzania. J Midwifery Womens Health. 2001; 46(4):248-257. doi: 10.1016/S1526-9523(01)00133-7.

8. Badr LK. Further psychometric testing and use of the Maternal Confidence Questionnaire. Issues Compr Pediatr Nurs. 2005; 28(3):16374. doi: 10.1080/01460860500227572.

9. Kuo CP, Chuang HL, Lee SH, Liao WC, Chang LY, Lee MC. Parenting confidence and needs for parents of newborns in Taiwan. Iran $\mathbf{J}$ Pediatr 2012;22(2):177-84. 8

10. United Nations Children's Fund. Accelerating efforts to eliminate child marriage in Africa. New York: UNICEF, 2017.

11. Langlois ÉV, Miszkurka M, Zunzunegui MV, et al. Inequities in postnatal care in low- and middle-income countries: a systematic review and meta-analysis. Bull World Health Organ 2015; 93:259-70.

12. Mirghafourvand M, Mohammad-AlizadehCharandabi S, Asghari Jafarabadi M, Soltanpour S. Psychometric properties of the Iranian version of the inventory of functional status after childbirth (IFSAC). Iran Red Crescent Med J. 2017; 19(5):e30210. doi:10.5812/ircmj.30210.
13. African Union. Campaign to end child marriage in Africa. The Effects of Traditional and Religious Practices of Child Marriage on Africa's Socio-Economic Development. A Review of Research, Reports and Toolkits from Africa. 2015. Available at: https://au.int/sites/default/files/documents/ 31018-doc-5465 ccmc africa report.pdf. (Retrieved on: 1 Apr 2018).

14. Gyesaw NYK, Ankomah A. Experiences of pregnancy and motherhood among teenage mothers in a suburb of Accra, Ghana: a qualitative study. Int J Women's Health. 2013; 5:773-80.

15. Josephine D., Self-Perceptions of Parenting among Adolescent Mothers J Perinat Educ. 2017; 16(1): 16-23.

16. Mimmie Claudine Ngum Chi Watts. Early motherhood: a qualitative study exploring the experiences of African Australian teenage mothers in greater Melbourne, Australia BMC Public Health. 2015; 15: 873.

17. Neal S, Channon AA, Chintsanya J. The impact of young maternal age at birth on neonatal mortality: Evidence from 45 low and middle income countries. PLoS One 2018; 13:e0195731.

18. Rikuya H A longitudinal study of socioeconomic status, family processes, and child adjustment from preschool until early elementary school: the role of social competence.

19. Ju-young Ha, Yoon-ji KimFactors Influencing Self-confidence in the Maternal Role among Early Postpartum Mothers Korean Journal of Women Health Nursing 2013; 19(1): 48-56

20. Adedokun O, Adeyemi O, Dauda C. Child marriage and maternal health risks among young mothers in Gombi, Adamawa State, Nigeria: implications for mortality, entitlements and freedoms. Afr Health Sci 2016; 16:986-99. 22. 